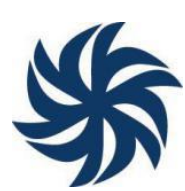

\title{
LEGISLAR EM TEMPOS DE PANDEMIA: COMO A COVID-19 TEM IMPACTADO A PRODUÇÃO DOS SENADORES BRASILEIROS?
}

\section{LEGISLATING IN TIMES OF PANDEMIC: HOW DID COVID-19 IMPACT THE PRODUCTION OF BRAZILIAN SENATORS?}

\section{LEGISLAR EN TIEMPOS DE PANDEMIA: ¿CÓMO IMPACTÓ EL COVID-19 EN LA PRODUCCIÓN DE SENADORES BRASILEÑOS?}

\author{
Barbara Tayanne Oliveira da Silva ${ }^{1}$ \\ João Vitor Costa ${ }^{2}$ \\ Adrián Albala ${ }^{3}$
}

\begin{abstract}
Resumo: A pandemia produzida pelo Covid-19 colocou os diversos poderes frente a dois objetivos: 1) conseguir se organizar e ser eficiente apesar da quarentena; e, sobre tudo 2) responder de forma eficiente e rápida às necessidades e urgência sanitária e social. Realizamos aqui uma análise do desempenho do senadores, em termo de apresentação (produção) e aprovação (efetividade) de projetos de lei durante a pandemia, e comparamos esses dados com os de uma período normal. Os resultados indicam que a pandemia não só não impactou negativamente em nenhum dos dois aspectos, como que, pelo contrário, parece ter tido um impacto positivo tanto no volume (quantidade) de propostas apresentadas e na celeridade em aprovar as propostas. $\mathrm{O}$ teor (qualitativo) das propostas também ficou impactado com um incremento significativo das propostas de saúde.
\end{abstract}

Palavra-chave: Senado; Covid-19; Produção legislativa.

\begin{abstract}
The pandemic produced by Covid-19 placed the various powers in front of two objectives: 1) to be able to organize and be efficient despite the quarantine; and, above all, 2) respond efficiently and quickly to health and social needs and urgency. Here we perform an analysis of the senators' acting, in terms of presentation (production) and approval (effectiveness) of bills during the pandemic, and we compare these data with those of unnatural periods. The effects denote that the pandemic not only did not hurt either aspect but that on the contrary, it seems to have had a positive impact both on the volume (quantity) of proposals submitted and on the speed with which the proposals were approved. The (qualitative) content of the proposals was also impacted by a significant increase in health proposals.
\end{abstract}

Keywords: Senate; Covid-19; Legislative Production.

Resumen: La pandemia producida por la Covid-19 colocó a los distintos poderes frente a dos objetivos: 1) poder organizarse y ser eficiente a pesar de la cuarentena; $y$, sobre todo, 2) responder con eficacia y rapidez a las necesidades y urgencias sanitarias y sociales. Realizamos aquí un análisis de la actuación de los senadores, en términos de presentación (producción) y aprobación (vigencia) de proyectos de ley durante la pandemia, y comparamos estos datos con los del período antinatural. Los efectos denotan que la pandemia no solo no afectó ninguno de los dos aspectos sino que, por lo contrario, parece haber tenido un impacto positivo tanto en el volumen (cantidad) de propuestas presentadas como en la rapidez con la que

\footnotetext{
${ }^{1}$ Graduanda em Gestão de Políticas Públicas (GPP), Universidade de Brasília.

${ }^{2}$ Graduando em Ciência Política, Instituto de Ciência Política, Universidade de Brasília

${ }^{3}$ Doutor em Ciência Política, Universidade de Sorbonne, Paris III (França). Professor no Instituto de Ciência Política (IPOL), Universidade de Brasília (UnB), Contato: aalbala@unb.br
} 
se aprobaron. El contenido (cualitativo) de las propuestas también se vio afectado por un aumento significativo en las propuestas de salud.

Palabras clave: Senado; Covid-19; legislativo; Producción legislativa.

\section{Introdução}

O surto da Covid-19 no cenário internacional colocou os decisores políticos frente à necessidade urgente de mobilização, a fim de conter a disseminação do vírus. Se a responsabilidade e a visibilidade dessa ação é, teoricamente, principalmente o feito do governo federal, os legislativos têm tido atuações destacadas. Assim, no Brasil, a Câmara dos Deputados e o Senado Federal, adequaram suas atividades e têm trabalhado remotamente desde o início da pandemia, tendo como uma das aprovações mais importantes nas casas o Decreto $n^{\circ} 6 / 2020$, do qual pedia o reconhecimento de Estado de Calamidade Pública - permitindo que o Executivo gaste mais do que o previsto e a possibilidade de extrapolação das metas fiscais estabelecidas anualmente, a fim de custear ações de combate à pandemia do COVID-19.

No entanto, o debate e avaliação de projetos oriundos de outros poderes, geralmente o executivo, é apenas uma das prerrogativas do Congresso Nacional. A outra, não menos relevante, é a de propor e produzir leis. Neste quesito, existe um bom entendimento da literatura brasileira em ciências políticas olhando para a Câmara dos Deputados, enquanto ao processo e a produção legislativa, e na efetividade das propostas em se tornarem lei (CERDEIRA et al., 2018; AMORIM NETO; SANTOS, 2003; MIRANDA, 2008; LIMONGI; FIGUEIREDO, 1995). Já no que diz respeito à produção legislativa do Senado, o entendimento é muito menor. Chama, de fato, a atenção a falta de consideração do desempenho dos senadores pela literatura brasileira (RUBIATTI, 2017) e internacional (ALBALA, 2017), sendo essa câmara essencialmente considerada como câmara revisora quando não "carimbadora".

O estudo do acionador do Senado Brasileiro é particularmente relevante sendo o bicameralismo "a la brasileira" um dos mais incongruentes e simétricos do mundo ${ }^{4}$ (LIJPHART 2019), combinado com um federalismo descentralizado. Esses elementos combinados impactam dramaticamente na atuação dos senadores (ARAUJO, 2010). De fato, estudos recentes têm mostrado que os senadores não só apresentam, proporcionalmente, mais projetos de lei do que os deputados federais, como conseguem uma taxa de efetivação maior desses projetos (ALBALA $e t$ al. 2021).

\footnotetext{
${ }^{4}$ A Simetria está relacionada aos poderes constitucionais que cada Casa Legislativa possui, serão considerados bicameralismos simétricos os casos em que as Câmaras (alta e baixa) possuem igualdade ou semelhança no poder de intervenção do processo legislativo e a Incongruência está relacionada aos métodos de formação de ambas as Câmaras, sendo que são incongruentes os bicameralismos que apresentem diferentes métodos de formação dos corpos legislativos.
} 
Assim sendo, e buscando contribuir com uma ainda escassa literatura sobre o Senado Federal, o objeto dessa pesquisa foca na produção legislativa dos senadores nesse contexto particular de pandemia. O objetivo principal consiste em analisar o potencial impacto da pandemia, e as dificuldades atreladas ao fechamento do Congresso Nacional, sobre a produção legislativa dos senadores brasileiros, e sua efetividade em transformar projetos em lei.

Para isso, iremos comparar o volume quantitativo de projetos de lei ordinária apresentado pelos senadores durante a pandemia, com o mesmo período em sessões legislativas anteriores, correspondendo ao segundo ano das legislaturas desde 2000-2020. Também consideramos a dimensão qualitativa, ou seja, os tópicos dos projetos apresentados e aprovados, comparando-os com os dos períodos anteriores. Finalmente, analisaremos a efetividade dos senadores em aprovar seus projetos em leis. Os dados analisados proveem do repositório oficial do Senado ${ }^{5}$, o repositório do Senado sobre a atividade durante a pandemia ${ }^{6}$, bem como informações adicionais via Secretaria de Gestão de Informação e Documentação (SGIDOC) ${ }^{7}$. Dessa forma, a pergunta central desta pesquisa plateia se e como a pandemia tem afetado o desempenho dos Senadores em termos de produção e efetividade legislativa?

A continuação faremos uma breve apresentação do processo legislativo de tramitação de projetos de leis. Logo, apresentamos nossas hipóteses e metodologia. Depois, apresentamos os resultados para concluir com potenciais desdobramentos dessa pesquisa.

\section{As alternativas no processo legislativo}

As proposições legislativas representam uma parte significativa do processo de produção de políticas aos parlamentares por oferecer ganhos com um custo baixo, visto que, possuem diversos recursos para a sua produção. A tramitação dessas proposições pode ser dividida em três etapas, a (i) iniciação, quando é apresentado a matéria legislativa para inserir determinada política por uma via legislativa; (ii) a fase da apreciação se dá na deliberação pelos demais parlamentares, com a possibilidade do auxílio de caráter opinativo de outros atores políticos; (iii) e a conclusão, ou seja, o resultado final da proposição, caracterizada no pela aprovação ou arquivamento da proposta $^{8}$ (GOMES, 2011; 2012; SOUZA, 1998).

\footnotetext{
${ }^{5}$ Acessível em: https://www25.senado.leg.br/web/atividade/materias

${ }^{6}$ Acessivel em: https://www25.senado.leg.br/web/atividade/materia/covid-19

${ }^{7}$ Acessivel em: https://www12.senado.leg.br/transparencia/formtransparencia

${ }^{8}$ Como apontado por Gomes (2013), é necessário que as características de sucesso ou falha sejam relativizados, uma vez que o objetivo pode não estar concentrado somente na aprovação de projeto semelhante ou mesmo ser um objetivo simbólico para debater o tema.
} 
Alguns estudos apontam que as condicionantes para o sucesso de uma proposição podem variar conforme a via legislativa optada pelo parlamentar e outros fatores, como o tema abordado e se o autor compõe ou não a coalizão. Apesar disso, os ganhos para os parlamentares no processo legislativo já podem ser percebidos e mensurados na apresentação da matéria, uma vez que admite um posicionamento sobre determinado assunto em certo período e assim presta serviço ao seu eleitorado. A literatura aponta esse tipo de ganho como simbólico, já que na apresentação, não há uma garantia factual de que a proposta se concretizará (ARAUJO, 2010; GOMES, 2012; FIGUEIREDO; LIMONGI, 1996).

Caso o parlamentar opte pela opção ordinária, ou seja, apresente um projeto de lei ordinária (PL), a nível estratégico, se encontraria em uma posição melhor do que se optasse por outro tipo de proposição, dada a menor necessidade de apoiamento e possibilidade de apresentação de matérias correlatas ${ }^{9}$. Apesar disso, essa via legislativa também possui limitações, como a possibilidade de veto presidencial e o arquivamento por tempo ou preferência ${ }^{10}$. Vale ressaltar ainda que no Brasil existem diferenças regimentais em relação ao processo legislativo entre a Câmara dos Deputados e o Senado Federal, que podem influenciar substancialmente o processo desde a apresentação (GOMES, 2011).

Ainda assim, não existem muitos estudos que diferenciam ou mesmo abordam a apresentação de proposições somente pelo Senado Federal, apenas tipificando-o como uma casa meramente revisora das matérias vindas da Câmara dos Deputados. No entanto, os poucos estudos existentes que demonstram a proatividade dos senadores frente a câmara baixa, o reconhecem como um órgão relevante na produção de políticas sobre determinados temas sanitários e de resposta a problemas econômico-financeiros ${ }^{11}$ (GOMES; CARVALHO; REIS, 2009; ALBALA et al., 2021).

\footnotetext{
${ }^{9}$ Os projetos de lei ordinária são aprovados com a maioria dos votos (maioria simples), desde que esteja presente no Plenário a maioria absoluta dos deputados (257).

${ }^{10} \mathrm{O}$ arquivamento por tempo se dá ao fim de cada legislatura a todas aquelas matérias em tramitação exceto nos casos de: autoria da Câmara dos Deputados; de senadores que permanecem no mandato ou foram reeleitos; apresentadas no último ano do mandato; que tenha parecer favorável das comissões; de competência exclusiva do Congresso Nacional; de competência privativa do Senado Federal; ou de sustação de processo contra Senador em andamento no Supremo Tribunal Federal. Já o arquivamento por preferência se dá quando a matéria é apensada a outra, passando assim a um status secundário. Caso a matéria principal seja aprovada, as matérias secundárias, se não incluídas por meio de substitutivo, serão arquivadas.

${ }^{11}$ Alguns estudos já apontaram as instituições brasileiras possuem um importante papel na agilidade de responder sobre assuntos relacionados a saúde, educação e crises econômico-financeiras como apontado por Melo (2008) e Langoni (2010).
} 


\section{A produção de projetos de lei}

Como apontado em outros estudos, as motivações políticas podem extrapolar a questão da saúde, quando esta envolve diversos estímulos, principalmente internacionais, e assim é provocando um constrangimento para que sejam tomadas decisões (BAPTISTA, 2010). Desta maneira, como em outras situações que exigiram respostas rápidas sobre assuntos relativos ao setor da saúde, o Legislativo possui uma motivação maior para atuar do que em momentos de maior estabilidade sanitária. O presente estudo optou por observar apenas o Senado Federal, com a intenção de comprovar um maior interesse de atores do legislativo em atuar do que em outros períodos e desassociar da instituição o papel de mero carimbador ${ }^{12}$. Além disso, o contexto excepcional derivado da pandemia oferece uma janela de oportunidade (KINGDON, 1995) extremamente valiosa para os senadores, em termos de visibilidade de ação para, posteriormente, prestação de contas (CAREY, 2009), constituindo assim bons resultados em vista à reeleição (PAPP; RUSSO, 2018) Dito isso, colocamos a primeira hipótese a ser testada:

H1- Devido ao contexto de maior exposição midiática derivado da pandemia, espera-se um aumento expressivo do número de PL apresentado pelos Senadores no primeiro período da pandemia do COVID-19 em comparação com mesmo período dos segundos anos das legislaturas anteriores.

\section{Classificação dos Projetos de Lei Ordinária}

O estudo do teor qualitativo dos projetos de lei consiste numa ferramenta relevante para entender as intenções dos parlamentares brasileiros, porém existem entraves metodológicos. Lemos (2001) já observou o fenômeno, demonstrando que os dois assuntos menos apresentados pelos parlamentares seriam assuntos fiscais e orçamentários - o segundo se trata de competência privativa do Executivo a sua apresentação. Além disso, existem outras barreiras constitucionais explicam essa postura do legislativo quanto a esses dois assuntos, visto que, são temas cruciais para consecução de políticas públicas e podem beneficiar regiões e clientelas específicas (NETO; SANTOS, 2003; LEMOS, 2001). Assim, as temáticas de teor social, econômico, jurídico e administrativo tomam força nas apresentações dos parlamentares.

As temáticas sociais se apresentam, tradicionalmente como predominantes na produção legislativa dos Deputados entre 1985-1999, correspondendo a quase metade das leis

\footnotetext{
${ }^{12}$ Vale ressaltar que a literatura aponta o primeiro ano de cada legislatura como o de maior produção legislativa já que possui maiores incentivos e um campo mais favorável para o sucesso de matérias, principalmente econômicas, e que nos demais anos espera-se uma redução significativa.
} 
transformadas em lei: 129 leis sociais de autoria dos deputados federais brasileiros promulgadas nesse período tratam de temática de i) regulamentação das vendas a prazo; ii) definição do que são relações estáveis entre homem e mulher; iii) distribuição gratuita de medicamentos a pessoas portadoras do vírus do HIV; iv) isenção de impostos para a aquisição de automóveis por deficientes físicos; v) regulamentação da doação de órgãos humanos, etc. Já as proposições administrativas e econômicas juntas perfizeram quase um terço de todos os projetos de lei ordinária da amostra. Esse número se explica pela necessidade de apresentar projeto que tenham impacto direto sobre os cidadãos, com o objetivo de maximizar a visibilidade do parlamentar e, dessa forma, a chance de ser reeleito (AMORIM NETO; SANTOS, 2003).

Baptista (2010) analisou a produção legislativa em saúde aprovado nos anos de 19902006 evidenciando o papel central do poder executivo nessa área. As propostas de autoria do Legislativo nesse período, quando não encontraram respaldo no Executivo, seguiram trâmites mais lentos e estiveram pautadas pela agenda Executiva (BAPTISTA, 2010). Com isso, é importante destacar a atuação dos parlamentares na apresentação de propostas com temáticas importantes, não somente de forma simbólica, mas que se encaixam no momento e preenchem a agenda do executivo para combate da pandemia.

Como mencionado anteriormente, existem poucos estudos que abordam a produção legislativa do Senado. Dessa forma, em base aos estudos sobre a Câmara, podemos esperar que a crise sanitária decorrente da pandemia, não somente tenha levado a um aumento na produção legislativa, bem como uma alteração das temáticas apresentadas, reverberando intenções setoriais dos senadores. Desta maneira, podemos assumir que os parlamentares se encontram com janelas de oportunidades abertas para legislarem sobre diversos temas nesse período (GOTTEMS, 2013). Ainda mais que um contexto emergencial tende a favorecer a apresentação e adoção de projetos alocados à solução ou mitigamento dos efeitos derivados desse contexto. Esse comportamento seria, assim, parecido ao comportamento de management emergencial ou de desastre ambiental (FARAZMAND, 2014; GLASSER et al., 2011; BOIN, 2009; JANIS, 1989). Assim a nossa segunda hipótese postula:

H2- O contexto emergencial derivado da pandemia teve um impacto nos tópicos apresentados nos PL, em termos qualitativos, com crescimento de temáticas de cunho sanitário, quando comparado com o mesmo período das legislaturas anteriores.

\section{Da apresentação à aprovação}

O momento de deliberação de uma matéria é importante para mensurar a atuação dos parlamentares e preocupação com o eleitorado, principalmente no momento de calamidade pública. Dessa forma, o contexto da pandemia constitui um marco extraordinário pela questão de grande urgência em que diversos setores que estão sendo afetados pela pandemia, e para o qual 
são necessárias soluções céleres de políticas públicas para lidarem, entre outro, com o aspecto de saúde pública e a paralisação de setores da economia.

Além disso, com o início da pandemia, os regimentos internos de ambas as casas do Congresso Nacional receberam flexibilizações para proporcionar que os parlamentares conseguissem realizar as atividades de maneira remota utilizando do Sistema de Deliberação Remota (SDR) ${ }^{13}$. Dessa forma, e seguindo o modelo de management emergencial (SYLVES, 2019), podemos assumir que um contexto de crise ou de emergência sanitária impacta no processo de tomada de decisão, sendo propício para uma aceleração dos prazos legislativos. A nossa terceira hipótese estipula então:

H3 - O caráter emergencial decorrente da pandemia tendeu a acelerar o processo deliberativo levando a um aumento expressivo na taxa de aprovação de projetos de lei ordinária durante o primeiro período da pandemia.

\section{Dados e Metodologia}

A estruturação metodológica do presente artigo visa focar na análise dos projetos de lei ordinária do Senado (PL), não restringindo o papel de iniciação do processo legislativo somente a Câmara dos Deputados como de costume. Decidiu-se observar somente esse tipo de proposição pela sua posição positiva na tramitação em nível estratégico, podendo levar sua aprovação mais rápida, uma vez que pode ainda ser concretizado com o poder conclusivo e terminativo das comissões em ambas as casas ${ }^{14}$ (ARAÚJO, 2009). Assim essa via legislativa se diferencia dos projetos de lei complementar (PLP) e propostas as emendas constitucionais (PEC) que se tornam mais inflexíveis quanto à sua tramitação.

Em vista disto, foram coletados os projetos de lei ordinária (PL) de 2020, correspondendo ao período de 23 de março até 23 de julho, que foi concretizado pelo Decreto $n^{\circ}$ 6/2020 da pandemia causada pelo Novo Coronavírus (COVID-19) ${ }^{15}$. Esses dados foram, então, comparados com os segundos anos das legislaturas anteriores, correspondendo da $51^{\circ}$ legislatura até $55^{\circ}$ legislatura (1999-2018). Além disso, optamos por utilizar uma variável dummy, com o objetivo de identificar as proposições que tinham ou não relação com o COVID-19.

\footnotetext{
${ }^{13}$ Vale ressaltar que todas as comissões no Senado Federal estavam suspensas, desta maneira, os senadores passaram a proferir o relatório sobre as proposições apenas no Plenário. Assim, a tramitação nos primeiros meses da pandemia se concentram no uso do Sistema de Deliberação Remota (SDR) exclusivamente no Plenário do Senado.

${ }^{14}$ Mesmo quando há necessidade de deliberação no Plenário, o texto poderá ser aprovado em maioria simples com os presentes.

15 É importante ressaltar que esse período pode compreender o recesso parlamentar.
} 
A análise do conteúdo dos projetos de lei ordinária para observar as intenções temáticas dos senadores é uma solução metodológica possível, que possui um custo ao necessitar de uma interpretação com nível de subjetividade e ad hoc. Porém, optamos por utilizar um dicionário baseado na codificação realizada pela Secretaria de Informação Legislativa, chegando nos seguintes temas: i) administrativo, ii) jurídico, iii) social, iv) educação, v) saúde e vi) honorífico. O tema orçamentário foi excluído por dois motivos, primeiro se trata de competência privativa do Executivo, como já apontado nesse e outros estudos, e segundo o assunto comportou-se de forma nula nas amostragens realizadas - alguns estudos já apontaram uma insignificância do assunto na produção legislativa (DE LIMA; SILVA, 2017).

Ao analisar os temas dos projetos de lei apresentados pelos Senadores, os assuntos relacionados à saúde e educação, geralmente inseridos no assunto social foram observados separadamente. O objetivo é analisar o assunto de saúde de uma perspectiva individual, por se tratar de uma das áreas mais afetadas pela pandemia do COVID-19, retirando as mudanças em outros setores provocados pela situação sanitária. Além disso, a educação que necessitou se adequar a um novo cenário devido a medidas que paralisaram aulas presenciais - quando não foram suspensas - até que tomadas novas medidas para retorno gradual de forma virtual ou presencial.

No processo de votação optamos em dividir em três etapas básicas a (i) aprovação, (ii) deliberação e (iii) não-deliberação em relação ao Plenário do Senado Federal. A primeira etapa se concentra em todos os projetos de lei ordinária que foram apresentados e aprovados durante o período, excluindo aqueles que apesar de aprovados no intervalo de análise foram iniciados em outras datas, o objetivo é estabelecer condições parecidas para a tramitação. É comum no legislativo que as proposições se comportem de maneiras diferentes ao longo da tramitação, frequentemente é possível observar que proposições podem demorar de 7 dias para a aprovação até 1500 dias a contar de sua apresentação.

Já a segunda etapa se restringe a todos aqueles projetos que receberam alguma decisão sobre a matéria que não seja a de aprovação, isso aglomera todas matérias que foram rejeitadas, arquivadas ou retiradas no período. A deliberação simboliza apenas uma vontade de se concretizar o projeto, porém não acarreta em resultados factuais. A terceira etapa se resume em todos os projetos que foram apresentados e não receberam nenhuma decisão no Plenário, nesse ponto o senador apenas possui os frutos simbólicos de se posicionar sobre determinado assunto. Vale ressaltar que optamos por incluir nesse ponto as matérias com autoria dos deputados federais que foram apresentadas e enviadas ao Senado, a fim de observar a ação de aprovação e deliberação dos senadores. 


\section{Resultados}

Araújo (2009) mostrou que os primeiros anos iniciais de uma legislatura é marcado por uma crescente apresentação de projetos pelos senadores e elevada aprovação de proposição, já nos anos eleitorais há uma redução significativa nas apresentações e aprovações, ou seja, o segundo e quarto anos de cada legislatura. O gráfico 1 mostra um aumento expressivo na apresentação de proposições no período de março a julho de 2020 (segundo ano da $56^{\circ}$ legislatura), um total de 403 proposições legislativas de lei ordinária com relação com a COVID19 que, em comparação com a média de 157,2 dos segundos anos das legislaturas anteriores (1999-2018), houve um aumento expressivo de $256 \%$.

Com isso, o total de projetos de lei ordinária apresentados nesse período de 2020 corresponde a 637, cerca de 403 possuíam alguma relação com o COVID-19, correspondendo a $63 \%$ do volume total dos apresentados. Desta forma, podemos observar que o volume absoluto da apresentação somente relacionados com a COVID-19, parece confirmar nossa primeira hipótese, que postula um acréscimo na de apresentação de projetos de lei ordinária, mesmo em um ano eleitoral, por conta do caráter emergencial.

Gráfico 1 - Produção de projetos de lei no Senado Federal (2000-2020).

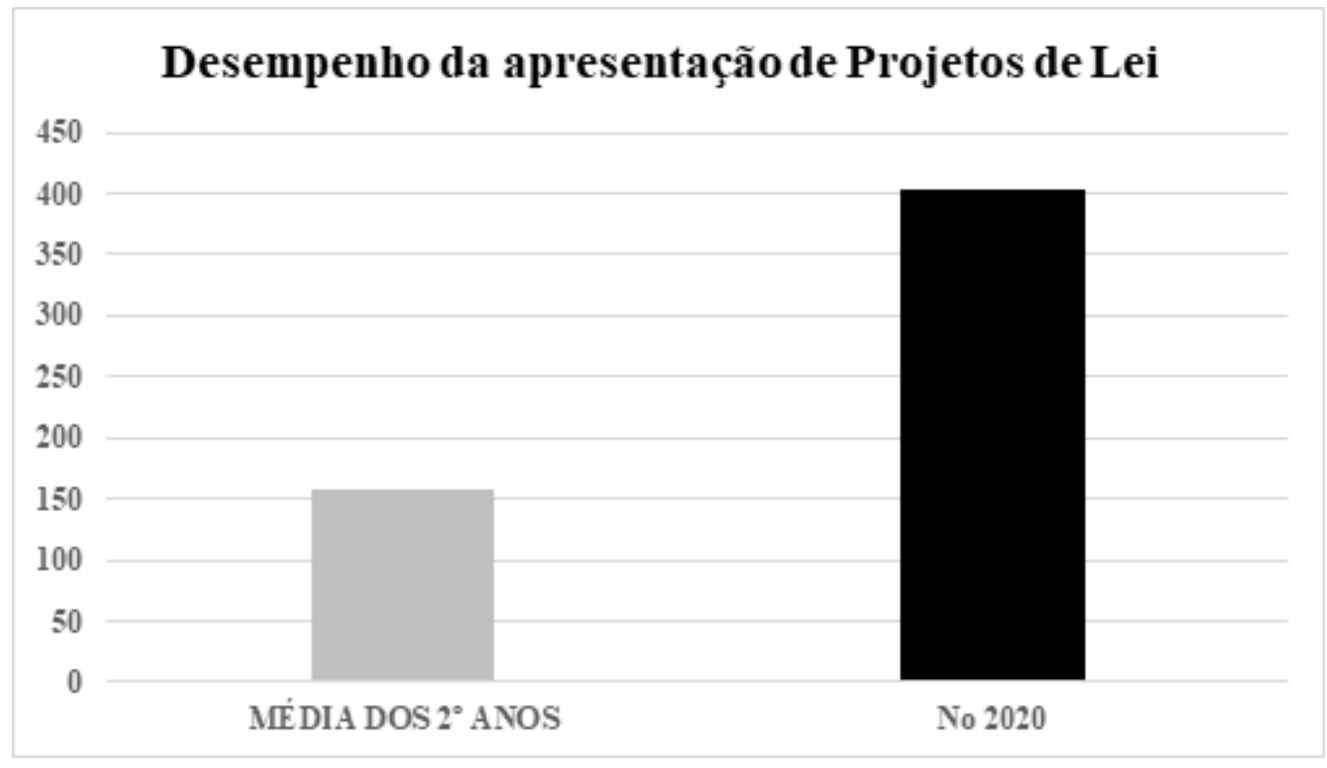

Fonte: Elaborado pelos autores com dados do portal Senado Federal. 
O gráfico 2 mostra os tópicos dos projetos de lei apresentados pelos Senadores brasileiros no período de março a julho dos segundos anos da $50^{\circ}$ até $54^{\circ}$ legislatura em comparação com o mesmo período de 2020, com os projetos que possuíam uma relação com a pandemia. De início, é possível visualizar que a iniciativa legislativa da câmara alta aumentou progressivamente em 2020 em comparação os segundos anos das legislaturas anteriores, como explicitado anteriormente. Os projetos com assuntos jurídicos, sociais e econômicos são os mais apresentados em ambos os cenários analisados - com e sem a pandemia, porém analisado um crescimento muito expressivo nos assuntos econômicos em relação aos demais. Os projetos de educação e honoríficos foram os menos apresentados no período de 2020, porém, nos anos anteriores, os temas honoríficos e de saúde foram os menos apresentados, mostrando um crescimento expressivo na apresentação de projetos de cunho sanitário. Essa alteração no padrão dos projetos de saúde, chamou atenção ao ultrapassar o número absoluto das proposições apresentadas do tema administrativo, demonstrando uma clara preocupação por parte dos senadores com a temática sanitária nesse período.

Já o gráfico 3, que demonstra o aumento de produção por tema em forma percentual, é observado um maior aumento nas proposições apresentadas dos setores da saúde e da economia e também um aumento expressivo nos temas de social e administrativo. Já o tema jurídico e de educação não se apresentaram distante da média das legislaturas anteriores e o honorífico se comportou negativamente. Vale ressaltar que todos os setores foram atingidos de alguma forma, mas o aumento expressivo em um tema específico traduz as intenções setoriais dos senadores naquele período, onde se concentra os esforços. Dessa forma, a nossa segunda hipótese se verifica. 
Gráfico 2 - Padrão de temas dos projetos de lei mais apresentados no Senado Federal (Média dos segundos anos das legislaturas entre 2000-2016 comparado com 2020).

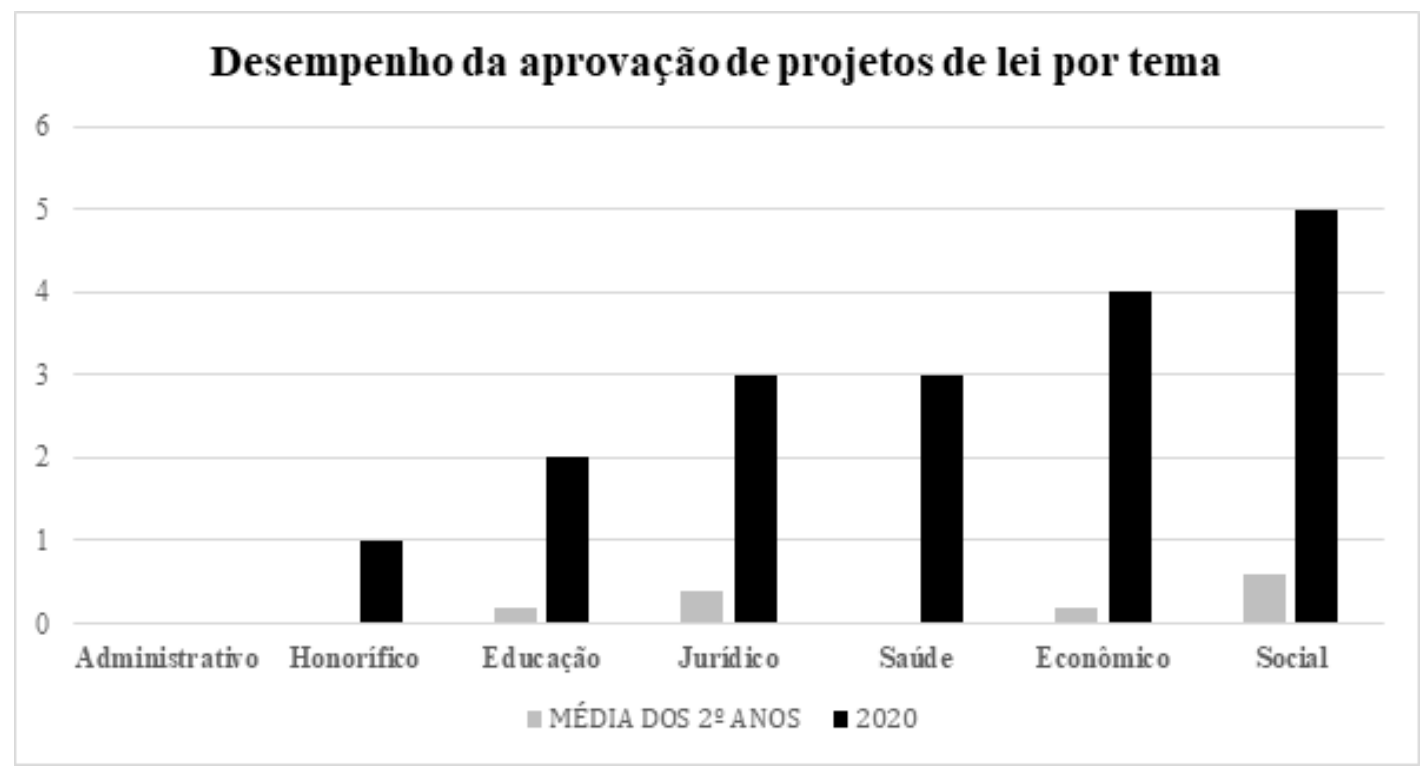

Fonte: Elaborado pelos autores com dados do portal Senado Federal.

Gráfico 3 - Aumento da apresentação por temas dos projetos de lei.

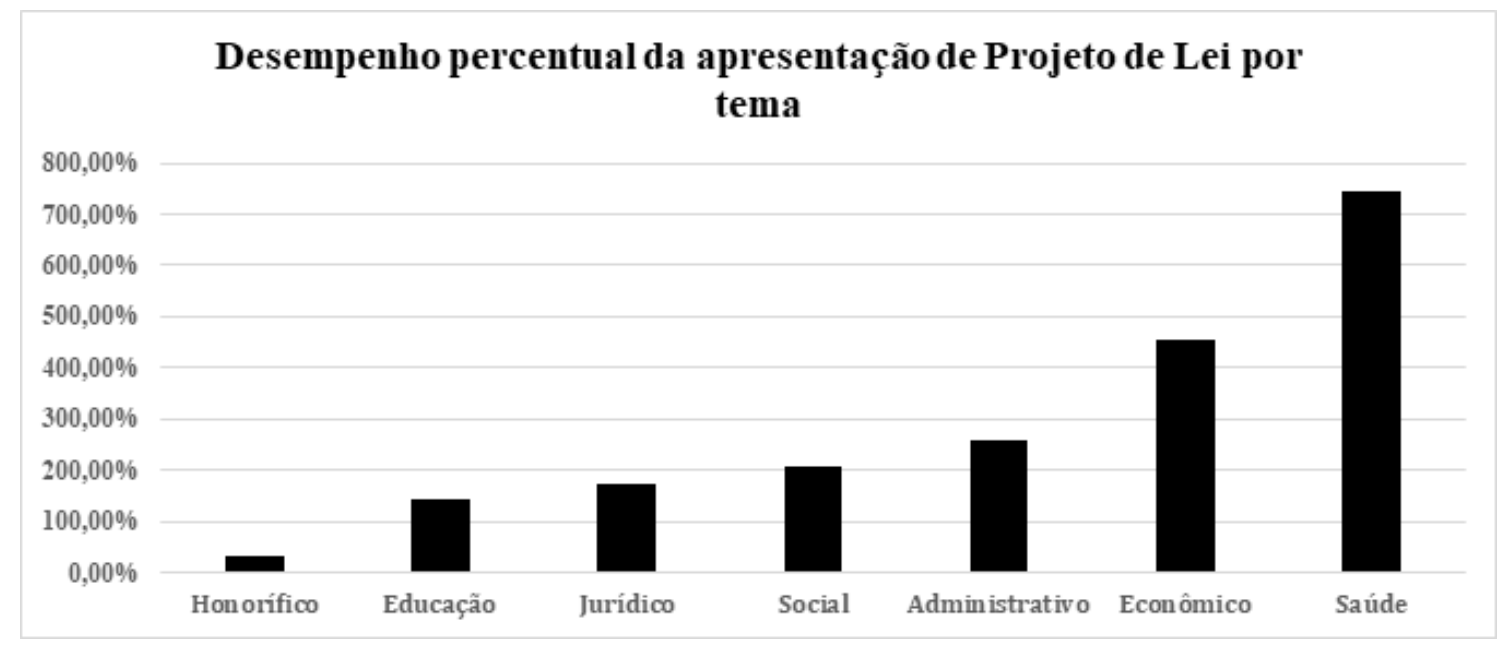

Fonte: Elaborado pelos autores com dados do portal Senado Federal.

No que atinge a nossa terceira hipótese, o gráfico 4 mostra um aumento significativo na aprovação de proposições em $1286 \%$ durante o período da pandemia. O aumento percentual da aprovação dos projetos pode indicar maior mobilização por parte dos senadores de não somente obter resultados simbólicos com a apresentação, mas de concretizar as proposições e lograr 
respostas mais factuais na pandemia (GOMES, 2012). Além disso, o presente estudo reforça ainda que um maior índice de aprovação dos senadores em um prazo estreito pode se dá pelos diversos grupos de interesses envolvidos e atingidos de alguma maneira pela pandemia com o constrangimento na tramitação de ensejo urgente de medidas paliativas que mitiguem os efeitos. Assim os senadores são estimulados em concretizar os pleitos que poderão ser específicos (BAPTISTA, 2010).

Não obstante, os gráficos 5 e 6 trazem o desempenho da aprovação dos Projetos de Lei Ordinária (PL) por tema em números absolutos e percentual, respectivamente. Assim, é observado a concentração de aprovação dos senadores em determinados temas, como Econômico e Educação, com aumentos de $2000 \%$ e $1000 \%$, nessa ordem. Ainda assim, os temas Social, Jurídico, Saúde e Honorífico também apresentaram aumento por essa ordem, apenas o tema Administrativo não apresentou nenhum aumento. Vale ressaltar que, embora o tema possa compreender uma maior parcela da aprovação em números absolutos, não necessariamente resulta no maior aumento de aprovação, podendo se tratar de um tema com uma taxa de deliberação significativa.

Gráfico 4 - Aprovação dos projetos de lei apresentados no Senado Federal.

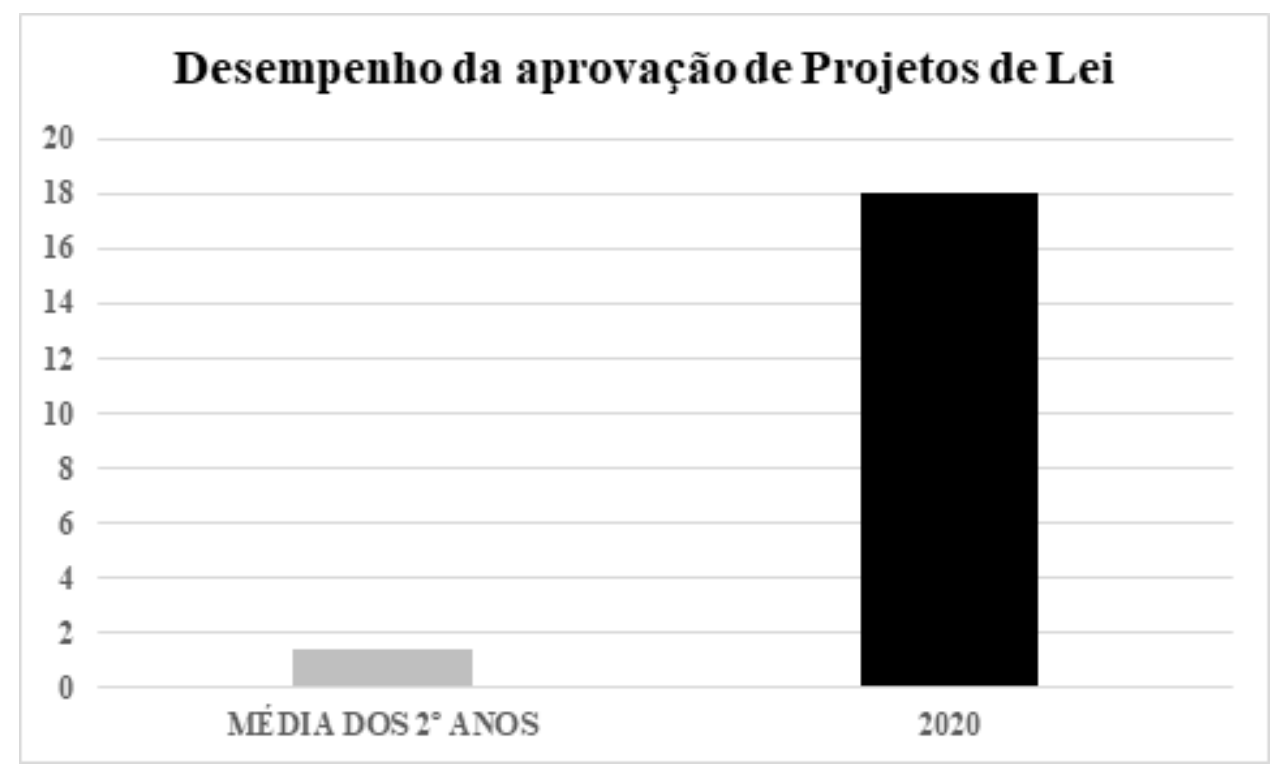

Fonte: Elaborado pelos autores com dados do portal Senado Federal. 
Gráfico 5 - Desempenho da aprovação dos projetos de lei apresentados por tema no Senado Federal.

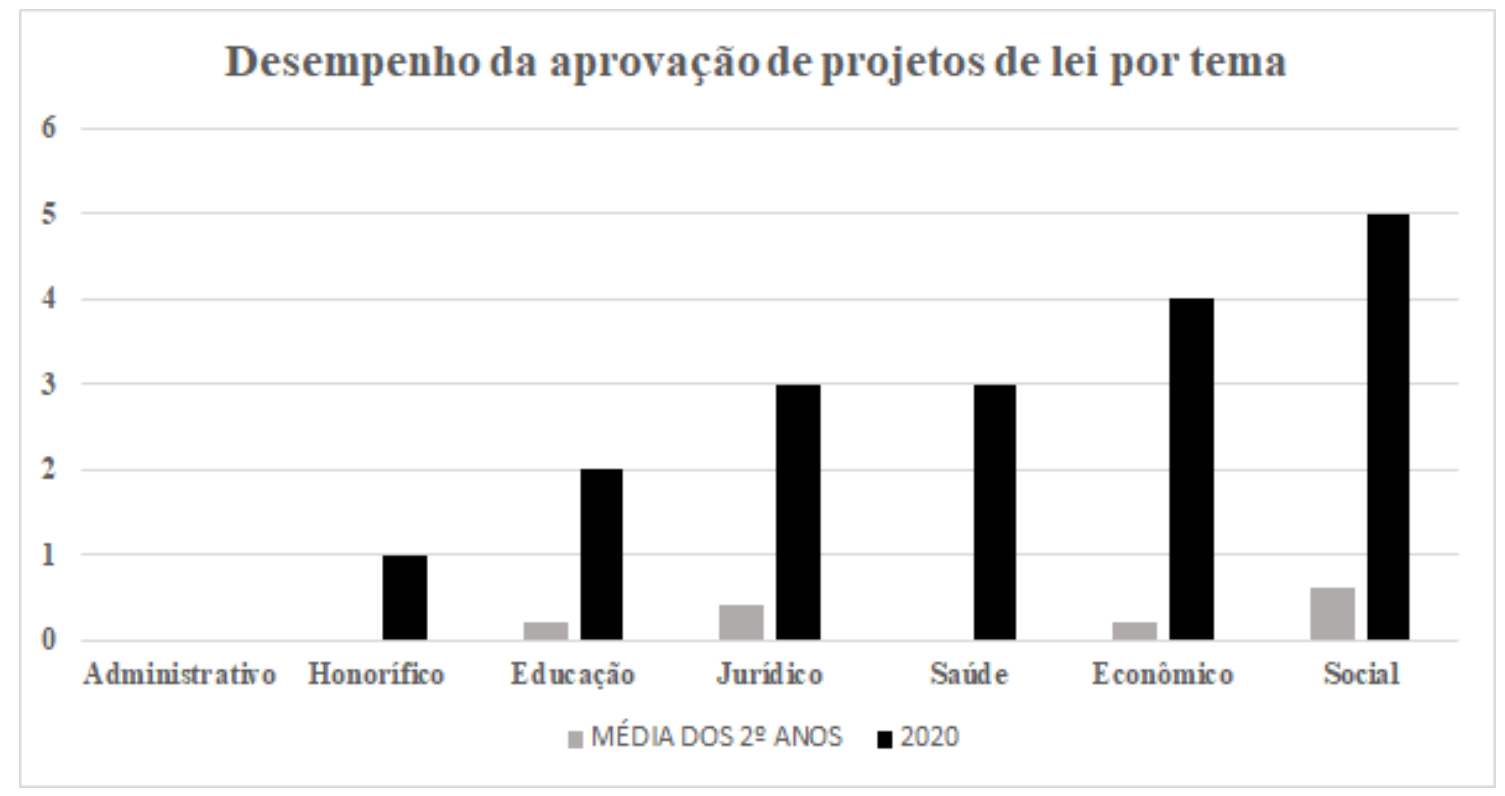

Fonte: Elaborado pelos autores com dados do portal Senado Federal.

Gráfico 6 - Desempenho da aprovação dos projetos de lei apresentados por tema no Senado Federal.

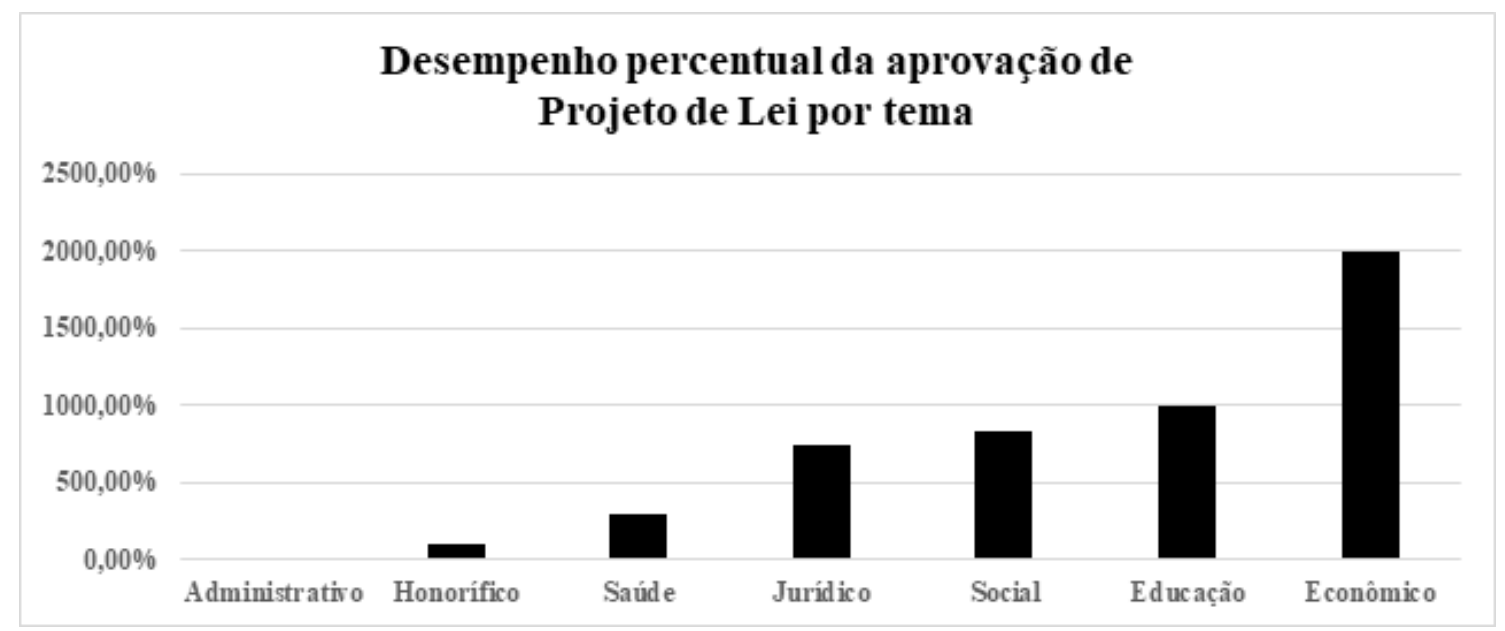

Fonte: Elaborado pelos autores com dados do portal Senado Federal.

Finalmente, a tabela 1 mostra a relação entre a apresentação e aprovação por tema dos projetos. Para isso, realizamos um teste de teoria usando o teste t de Student, que serve para medir as diferenças de médias entre duas bases. O teste mostra que apenas o tema Saúde apresentou a não rejeição de $\mathrm{H} 0$, ou seja, embora haja um incremento na apresentação de projetos com temática 
na saúde, esse incremento não é estatisticamente significativo. Para todos os demais temas, os testes indicam que existe uma diferença significativa entre as médias de apresentação e aprovação, confirmando, então, parcialmente, nossas Hipóteses 2 e 3.

Tabela 1 - Teste de hipóteses para a apresentação e aprovação dos Projetos de Lei (PL) por tema.

\begin{tabular}{ccccc}
\hline Tema & $\begin{array}{c}\text { Média de } \\
\text { apresentação }\end{array}$ & $\begin{array}{c}\text { Média de } \\
\text { aprovação }\end{array}$ & Teste-T & $\begin{array}{c}\text { Resultado do } \\
\text { Teste T }\end{array}$ \\
\hline Jurídico & 48,8333 & 0,8333 & 0,0002047141701 & Rejeita H0 \\
Administrativo & 17,1667 & 0 & 0,004873478843 & Rejeita H0 \\
Econômico & 39,8333 & 0,8333 & 0,02347420553 & Rejeita H0 \\
Social & 57,3333 & 1,3333 & 0,001095424648 & Rejeita H0 \\
Saúde & 16,1667 & 0,5000 & 0,05401574352 & Não rejeita H0 \\
Educação & 13,3333 & 0,5000 & 0,002902811886 & Rejeita H0 \\
Honorífico & 5,5000 & 0,1667 & 0,01356940732 & Rejeita H0 \\
\hline
\end{tabular}

Fonte: Elaborado pelos autores com dados do portal Senado Federal.

\section{Conclusão}

Em meio a uma pandemia, o objetivo do Poder legislativo é, a curto prazo, apresentar e aprovar proposições que possam ajudar no combate. Preocupações com proposições no geral referente a outros assuntos são deixados em segundo plano. No caso brasileiro, o período de Março a Julho de 2020 - que corresponde ao segundo ano da $55^{\circ}$ legislatura -, primeiro período de Calamidade Pública causada pelo Covid-19, demonstrou um crescimento significativo na apresentação e na deliberação de Projetos de Lei por parte dos Senadores, em comparação com os segundos anos das legislaturas anteriores (2000-2016), crescimento esse que pode ser explicado pela urgência de legislar em um momento crítico de Saúde pública no país, demonstrando a força dessa casa e a interferência nas decisões políticas através da apresentação e aprovação de leis para a população.

Nos resultados apresentados, ao comparar o primeiro período de pandemia com os segundos anos das legislaturas anteriores, foi percebido um aumento significativo tanto na 
apresentação quanto na deliberação e aprovação dos projetos de lei. Esse impacto na produção legislativa dos senadores confirmou as hipóteses apresentadas que, apesar de legislarem mais sobre saúde, apresentaram também um aumento expressivo nas apresentações de outros assuntos, verificando a relação de maior produção como um todo dos senadores no período de Calamidade Pública.

Apesar disso, o presente estudo não analisou os Estados, os Partidos dos Senadores, a relação com o Poder Executivo e os deputados federais, elementos importantes para uma análise mais aprofundada e compreender perguntas como: A atuação dos senadores e suas relações com Estado que o elegeram foram impactadas pela pandemia? Uma relação com o Executivo proporcionou um impacto na aprovação de projetos durante o período de pandemia? Os projetos de temáticas da saúde representaram a maior fração dos projetos aprovados?

Por fim, é necessário que estudos futuros possam analisar a atuação dos senadores e levem em conta a importância da câmara alta no processo legislativo e promoção de políticas públicas em períodos de crise sanitária. Como também, possam realizar pesquisas que incluam outros países, e seus respectivos sistemas bicamerais, observando o desenvolvimento da pandemia no mundo com o processo de produção de legislações sobre o COVID-19.

\section{Referências}

ALBALA, A. Coalition Presidentialism in Bicameral Congresses: How does the Control of a Bicameral Majority Affect Coalition Survival?, Brazilian Political Science Review, v. 11, n. 2, 2017.

AlBAlA, A.; COUTO, L.; lOPES, A.; LiVRAMENTO, B. Uma Câmara Só Para Carimbar?: Produção Legislativa do Senado Brasileiro. 2021. [No prelo].

AMORIM NETO, O.; SANTOS, F. O segredo ineficiente revisto: o que propõem e o que aprovam os deputados brasileiros. Dados: Revista de Ciências Sociais, Rio de Janeiro, v. 46, n. 4, p. 661698, 2003.

ARAÚJO, P. M. Câmara alta e bicameralismo no Brasil: análise da produção legislativa a partir do senado federal (1989-2004). Revista de informação legislativa, v. 47, n. 187, p. 245-268, 2010

ARAÚJO, P. M. O bicameralismo no Brasil: argumentos sobre a importância do Senado na análise do processo decisório federal. Política \& Sociedade, v. 11, n. 21, p. 83-135, ago. 2012

ARAÚJO, P. M. O bicameralismo no Brasil: as bases institucionais e políticas do desempenho legislativo do Senado Federal (1989-2004). 2009.

BAPTISTA, T. W. F. Análise da produção legislativa em saúde no Congresso Nacional brasileiro (1990-2006). Cadernos de Saúde Pública, v. 26, n. 1, p. 97-109, 2010. 
BOIN, Arjen. The new world of crises and crisis management: Implications for policymaking and research. Review of Policy research, v. 26, n. 4, p. 367-377, 2009.

CAREY, J. Legislative Voting and Accountability. Cambridge: Cambridge University Press, 2009.

CARVALHO, E. L. D.; GOMES, F. D. B. C. Projetos de lei ordinária apresentados na câmara dos deputados entre 1999 e 2006: tramitação geral e dos relacionados à saúde. E-Legis: Revista Eletrônica do Programa de Pós-Graduação da Câmara dos Deputados, v. 2, n. 2, p. 32-44, jan./jun. 2009.

CERDEIRA, P. et al. Congresso em Números: a produção legislativa do Brasil 1988- 2017. Rio de Janeiro: FGV, 2018.

DE LIMA, E.D.; SILVA, S. S. Os limites do Poder Legislativo para atuar sobre políticas públicas. Revista de Direito Sociais e Políticas Públicas, v. 3, p. 101-118, 2017.

GLASSER, G. et al. Modeling and public health emergency responses: Lessons from SARS. Epidemics, v. 3, n. 1, p. 32-37, 2011.

FARAZMAND, A. Crisis and Emergency Management. Boca Raton: CRC Press, 2014.

FIGUEIREDO, A; LIMONGI, F. Congresso Nacional: organização, processo legislativo e Produção Legal. Caderno de Pesquisas CEBRA, São Paulo, n. 5, 1996.

GOMES, F. B. C. Interações entre o Legislativo e o Executivo federal do Brasil na definição de políticas de interesse amplo: uma abordagem sistêmica, com aplicação na saúde. 2011Tese (Doutorado em Ciência Política) - Universidade Estadual do Rio de Janeiro, Rio de Janeiro, 2011.

GOMES, F. B. C. Cooperação, liderança e impasse entre o Legislativo e o Executivo na produção legislativa do Congresso Nacional do Brasil. Dados: Revista de Ciências Sociais, Rio de Janeiro, v. 55, n. 4, p. 911-950, dez. 2012.

GOTTEMS, L. B. D. et al . O modelo dos múltiplos fluxos de Kingdon na análise de políticas de saúde: aplicabilidades, contribuições e limites. Saúde Soc., São Paulo, v. 22, n. 2, p. 511-520, jun. 2013.

JANIS, I. Crucial Decisions: Leadership in Policymaking and Crisis Management. New York: The Free Press, 1989.

KINGDON, J. Agendas, Alternatives and Public Policies. 2.ed. New York: Longman, 1995.

LEMOS, L.; RANINCHESKI, S. O perfil sociopolítico dos senadores brasileiros. Senatus, Brasília, v. 2, n. 1, p. 33-39, 2001.

LEMOS, L. B. S. O Congresso Brasileiro e a Distribuição de Benefícios Sociais no Período 19881994: Uma Análise Distributivista. Dados: Revista de Ciências Sociais, Rio de Janeiro, v. 44, n. 3, p. 561-605, 2001.

LIJPHART, A. Modelos de Democracia: desempenho e padrões de governo em 36 países. Rio de Janeiro: Civilização Brasileira, 2019.

LIMONGI, F. e FIGUEIREDO, A. C. Partidos Políticos na Câmara dos Deputados: 19891994. Dados: Revista de Ciências Sociais, Rio de Janeiro, v. 38, n. 3, p. 497-524, 1995. 
MIRANDA, G. L. O comportamento dos partidos na Câmara dos Deputados e no Senado Federal (1991-2007). 2008.

PAPP, Z; RUSSO, F. Parliamentary Work, Re-Selection and Re-Election: In Search of the Accountability Link. Parliamentary Affairs, v. 71, n. 4, p. 853-867, 2018.

RUBIATTI, B. C. Sistema de resolução de conflitos e o papel do Senado como Câmara revisora no bicameralismo brasileiro. Revista Brasileira de Ciência Política, n. 23, p. 35-74, 2017.

SOUZA, H. Processo Legislativo. Porto Alegre: Sulina, 1998.

SYLVES, R. Disaster Policy and Politics: Emergency Management and Homeland Security. Londres: Sage, 2008. 